Case Report

\title{
Cystic lesion of the sella turcica: interesting case report and review of literature
}

\author{
Blessy B. Prabha ${ }^{1 *}$, Vijay Rangachari ${ }^{1}$, Priyamvadha Kovai ${ }^{2}$, Abha Verma ${ }^{3}$
}

\begin{abstract}
${ }^{1}$ Department of Otorhinolaryngology, Manipal Hospitals Whitefield, Bengaluru, Karnataka, India
${ }^{2}$ Department of Neurosurgery, Manipal Hospitals Whitefield, Bengaluru, Karnataka, India

${ }^{3}$ Department of Neuro-radiology, Manipal Hospitals Whitefield, Bengaluru, Karnataka, India
\end{abstract}

Received: 25 March 2021

Accepted: 03 May 2021

\author{
*Correspondence: \\ Dr. Blessy B. Prabha, \\ E-mail: blessybalaji@gmail.com
}

Copyright: (C) the author(s), publisher and licensee Medip Academy. This is an open-access article distributed under the terms of the Creative Commons Attribution Non-Commercial License, which permits unrestricted non-commercial use, distribution, and reproduction in any medium, provided the original work is properly cited.

\section{ABSTRACT}

Intrasellar arachnoid cysts are rare entities. High index of suspicion and precise radiological evaluation are the cornerstone for appropriate diagnosis and treatment. We present a symptomatic case of a sellar cystic lesion in a 52-year-old lady, who had complaints of decreased vision associated with diplopia of three months duration. Clinical evaluation showed bitemporal hemianopia. Magnetic resonance imaging of brain revealed features of sellar arachnoid cyst with the intracystic component similar to cerebrospinal fluid. She underwent endoscopic transnasal transsphenoidal excision of lesion. Her visual symptoms improved well on subsequent follow up. However infrequent, sellar arachnoid cyst should be borne in mind as differential diagnosis for any cystic sellar lesions, as they can mimic pituitary adenomas, either by impairment of pituitary hormonal function or by exerting pressure effects on optic chiasma. Evaluation modalities, therapeutic challenges and literature review are presented in this case report.

Keywords: Sellar cystic lesion, Arachnoid cyst, Transsphenoidal approach

\section{INTRODUCTION}

Arachnoid cysts are benign tumours of the arachnoid, they constitute around one percent of all intracranial spaceoccupying lesions. ${ }^{1}$ Among the cystic lesions of the sellar region, intrasellar arachnoid cysts are rare and contribute to about three percent of all intracranial arachnoid cysts. Most common sites of encounter are the Sylvian fissure followed by the cerebellopontine angle, the supracollicular area and the vermis. ${ }^{2,3}$

The differentiation of these cysts from other cystic lesions of the sellar region remains a challenge during preoperative evaluation as they are similar in terms of clinical presentation and imaging parameters.

Radiological features are the cornerstone for accurate preoperative diagnosis, planning and outcome in such cases.

\section{CASE REPORT}

A 52-year-old lady had presented with complaints of decreased vision with diplopia of three months duration. She had no history of associated headache, seizures or vomiting. There was no history suggestive of galactorrhoea or polyuria. She had attained menopause one and a half years ago. She was a known hypertensive and had history of hypothyroidism and was on thyroid supplements since many years.

Clinical examination, showed a reduction in visual acuity with bitemporal hemianopia. The neurological examination was otherwise unremarkable. Ophthalmology opinion was obtained and above findings were confirmed by perimetry. Magnetic resonance imaging (MRI) brain showed widened sella with evidence of a cystic lesion within, with suprasellar extension. 
The lesion appeared hypointense on T1w sequence (Figure 1), hyperintense on $\mathrm{T} 2 \mathrm{w}$ sequence (Figure 2) and hypointense on fluid attenuated inversion recovery (FLAIR) sequence. The lesion appeared isointense to cerebrospinal fluid (CSF). There was no evidence of hypointense peripheral rim around the lesion or intracystic mural nodule or fluid level within the lesion. The lesion measured approximately $2 \mathrm{~cm}$ anteroposteriorly, $2.4 \mathrm{~cm}$ craniocaudally and $1.9 \mathrm{~cm}$ transversely and was causing mass effect on intracranial segment of both optic nerves and optic chiasma. The intracranial segments of both optic nerves were splayed, displaced and compressed laterally and superiorly. The stretched pituitary tissue showed postcontrast enhancement. These features were suggestive of an intrasellar arachnoid cyst. Hormonal evaluation was normal and the endocrinologist advised continuation of the thyroid supplements with steroid cover during the perioperative period. She underwent endoscopic transnasal transsphenoidal excision under general anaesthesia. Intraoperatively, the cyst was exposed after opening the sellar floor (Figure 3). On opening the dura, clear watery fluid resembling CSF gushed out under pressure and the diaphragma sellae was seen descending down (Figure 4). The pituitary stalk was seen inferiorly and the chiasma was seen through the diaphragma. The cyst cavity was inspected. Cyst wall was removed piecemeal and sent for histopathological examination. The sellar cavity was then obliterated with fat graft and the dura reflected back and strengthened with a layer of fascia lata. Histopathological examination showed thin cyst wall composed of fibrous connective tissue focally lined by meningothelial cells which was consistent with arachnoid cyst. Postoperative period was uneventful. Visual acuity improved from bitemporal hemianopia to superotemporal quadrantanopia. Post-operative MRI after 6 months showed heterogenous hyperintensity suggestive of fat in T1w (Figure 5) and showed no CSF-like hyperintensity in the sella in T2w image (Figure 6).

There was no evidence of residual or recurrent disease. She has been on regular follow up for the past one year and has recovered without any neurological or endocrinological sequelae.

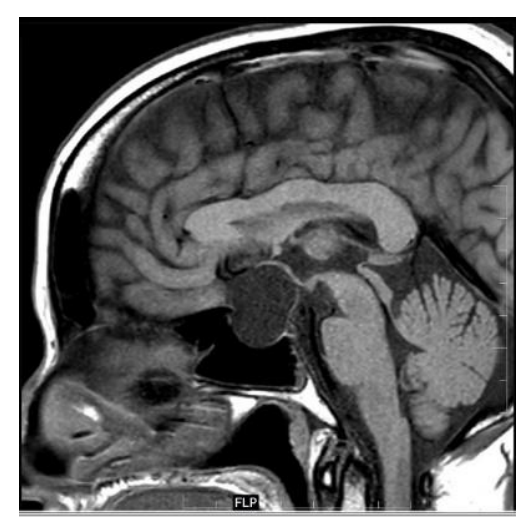

Figure 1: T1w MRI showing hypointense cystic lesion in sellar and suprasellar region.

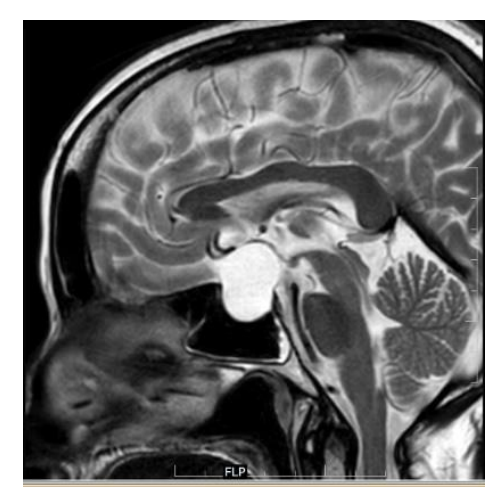

Figure 2: T2w MRI showing hyperintense lesion in sellar and suprasellar region suggesting CSF content.

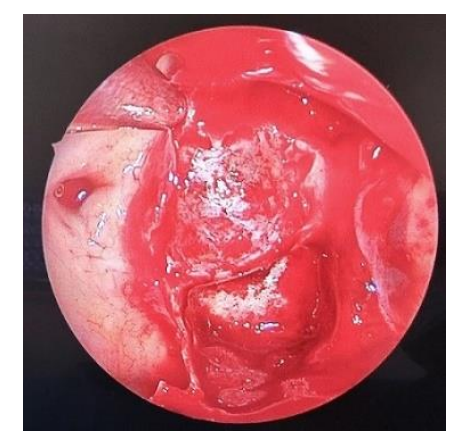

Figure 3: Arachnoid cyst seen after opening the sellar floor.

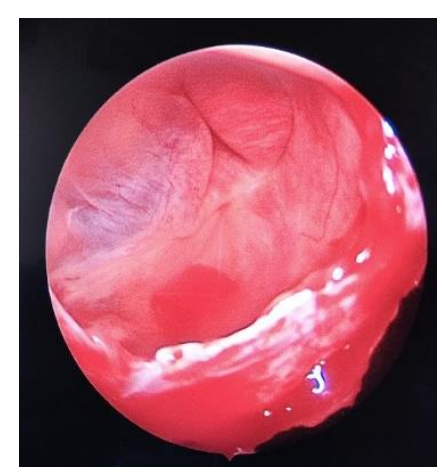

Figure 4: Diaphragma sella seen descending down after decompression of the arachnoid cyst.

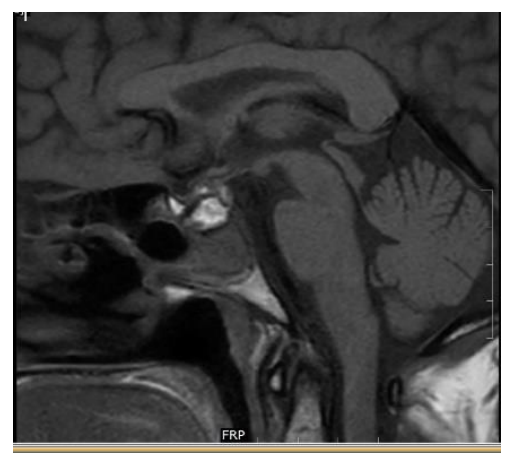

Figure 5: Post-operative T1w MRI showing fat as hyperintensity with no residual lesion. 


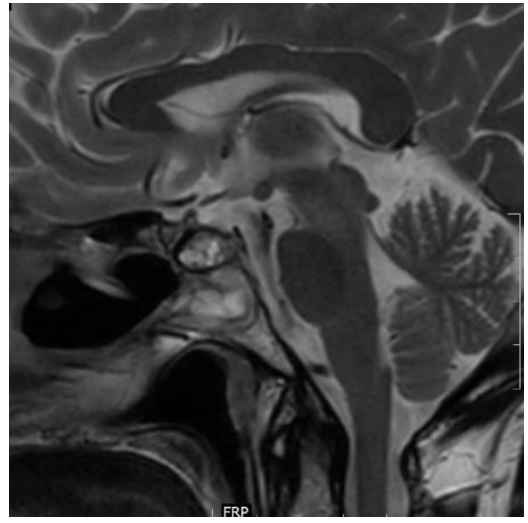

Figure 6: Post-operative T2w MRI showing no CSFlike hyperintensity in the sella.

\section{DISCUSSION}

Collection of CSF-like fluid within a cavity lined by arachnoid structures gives rise to an arachnoid cyst. They can develop anywhere along the cerebrospinal axis in subarachnoid space. ${ }^{4}$ Normally the diaphragma sellae has no arachnoid tissue beneath. Intrasellar arachnoid cyst can arise as result of herniation of basal arachnoid membrane through a defect in diaphragma sella. ${ }^{2}$ Benedetti et al states that there could be an association between primary empty sella syndrome and intrasellar arachnoid cyst in terms of etiopathogenesis. Intrasellar arachnoid cysts could be primarily formed by large subarachnoid space expanding and communicating within the sella turcica which could be isolated by closure of the communication due to some meningitic, hemorrhagic, or inflammatory event. ${ }^{5}$ Endocrine symptoms involving the gonadotropic axis such as infertility, impotence and others like menstrual irregularities were less common, panhypopituitarism was found on hormonal evaluation, few of them presented with complaints suggestive of optochiasmatic compression and hyperprolactinemia.

Radiological evaluation plays a key role in management of sellar cystic lesion. CT, MRI and CT cisternography can be done. Recently, cine MR imaging has been introduced for preoperative diagnosis. ${ }^{6}$ The various cystic lesions of the sellar region such as cystic adenomas, craniopharyngiomas, Rathke's cleft cysts, intrasellar arachnoid cysts can be differentiated based on radiological characteristics. Craniopharyngiomas are seen as heterogeneous, mixed consistency (solid/cystic) and calcified lesions whereas Rathke's cleft cysts and arachnoid cysts appear as smooth contour and homogeneous lesions. Rathke's cleft cysts are midline lesions, arise between the anterior and posterior pituitary and usually demonstrate an intracystic solid nodule.

MR signal intensity is based on its content, and most of them do not enhance but can have an enhancing rim of compressed pituitary tissue surrounding the cyst (Claw sign). Arachnoid cysts, on the other hand, appear homogeneous, contain CSF, show no contrast enhancement and can have pituitary gland flattened against the sellar walls. ${ }^{7}$ Since leptomeninges are absent in the sella turcica, intrasellar arachnoid cysts are not associated with normal CSF cisterns. ${ }^{4}$ These cysts can have layers of nonciliated meningothelial cells as lining epithelium. Rengachary and Watanabe have elaborated the features of arachnoid cysts. They have elucidated details like splitting of the arachnoid membrane, cyst wall having thick collagen and hyperplastic arachnoid cells and absent arachnoid trabeculations within cyst. If routine light microscopy findings are not able to differentiate arachnoid cysts from epithelial cysts, then immunohistochemical studies help to sort out the diagnosis as arachnoid cysts are positive for epithelial membrane antigen. ${ }^{2,3,8}$

Surgical treatment is essential for tissue diagnosis, reversal of pituitary dysfunction, and alleviation of signs of optochiasmatic compression and headaches. Intra operatively, sella turcica and sphenoid sinus must be sealed meticulously to reduce the incidence of CSF fistula which can result in meningitis. Effective sealing can also prevent prolapse of the optic structures in an emptied sella resulting in postoperative blindness. Partial pituitary insufficiency often recovers, whereas complete pituitary insufficiency frequently does not improve. Irreversible pituitary symptoms could result due to pulsatile mass effect resulting in gland atrophy. Transsphenoidal approach with good sealing of the sella can be followed for small intrasellar arachnoid cysts and craniotomy for large intrasellar arachnoid cysts with communication between the cyst and the suprasellar arachnoid cistern to avoid complications. ${ }^{4,6}$

Chances of recurrences are described even several years after initial surgical treatment. Therefore, there is a need for long term regular follow up. ${ }^{9}$

\section{CONCLUSION}

Intrasellar arachnoid cysts are very rare when compared to other cystic lesions, due to absence of leptomeninges in sella turcica and arachnoid membrane below the diaphragma sellae. Hence, clinicians should be aware of this condition and it should be borne in mind as a differential diagnosis of sellar cystic lesions. Presentation could be similar to a non-functional pituitary adenoma. MRI scans showing characteristic features of cystic intrasellar lesion with fluid that is iso or hyperintense to CSF play a key role in diagnosis and management.

Transsphenoidal or transcranial approach and drainage of the cyst with or without communication with suprasellar arachnoid cistern, the need for meticulous closure and packing are important to prevent postoperative complications such as CSF fistulae.

Funding: No funding sources Conflict of interest: None declared

Ethical approval: Not required 


\section{REFERENCES}

1. Starkman SP, Brown TC, Linell EA. Cerebral arachnoid cysts. J Neuropathol Exp Neurol. 1958;17(3):484-500.

2. Guduk M, Hamit AM, Sav A, Berkman Z. Intrasellar arachnoid cyst: A case report and review of the literature. Int J Surg Case Rep. 2016;23:105-8.

3. Rengachary SS, Watanabe I. Ultrastructure and pathogenesis of intracranial arachnoid cysts. J Neuropathol Exp Neurol. 1981;40(1):61-83.

4. Dubuisson AS, Stevenaert A, Martin DH, Flandroy PP. Intrasellar arachnoid cysts. Neurosurgery. 2007;61(3):505-13.

5. Benedetti A, Carbonin C, Colombo F. Possible aetiopathogenetic correlation between primary empty sella and arachnoid cyst. Acta Neurochir. 1977;38(3):269-78.
6. Miyamoto T, Ebisudani D, Kitamura K, Ohshima T, Horiguchi H, Nagahiro S. Surgical management of symptomatic intrasellar arachnoid cysts-two case reports. Neurol Med Chir. 1999;39(13):941-5.

7. Mangussi GJ, Gentil AF, Filippi RZ, Momesso RA, Handfas BW, Radvany J, et al. Sellar and suprasellar arachnoid cyst. Einstein. 2019;17(1):4269.

8. Prayson RA. Neuropathology Review. 2nd ed. Human Press; 2001: 230.

9. Murakami M, Okumura H, Kakita K. Recurrent intrasellar arachnoid cyst. Neurol Med Chir. 2003;43(6):312-5.

Cite this article as: Prabha BB, Rangachari V, Kovai P, Verma A. Cystic lesion of the sella turcica: interesting case report and review of literature. Int $\mathbf{J}$ Otorhinolaryngol Head Neck Surg 2021;7:1048-51. 